\title{
EVALUATION OF BUCCAL BONE LID TECHNIQUE USING PIEZOELECTRIC SURGERY IN SURGICAL EXTRACTION OF DEEPLY IMPACTED LOWER THIRD MOLAR (A CLINICAL AND RADIOGRAPHIC STUDY)
}

\author{
Yasmin A.Ali ${ }^{1 *}$ BDS Ahmed M. El-sabagh² PhD, Ahmed O. Sweedan ${ }^{3} P h D$.
}

\begin{abstract}
INTRODUCTION: Surgical removal of deeply impacted third molar is complicated most times with inferior alveolar nerve injury and developing large bony defects because of the deep situation of impacted tooth and limited visibility. Buccal bone lid technique using the piezoelectric device is a recent technique for surgical removal of such an impacted tooth to avoid these complications. As it allows accessibility and the accuracy of piezoelectric tips to cut through bone only without damaging adjacent tissues.

OBJECTIVES: The main aim of this study was to evaluate the efficiency of buccal lid technique using piezotome surgery in removal of deeply impacted third molar.

MATERIALS AND METHODS: Ten patients with deeply impacted lower third molar were subjected to surgical extraction using buccal lid technique. Clinical follow up was conducted after a 24-hours, 72-hours, one week, six months. Also, a radiographic investigation was performed immediately postoperative and after six months to estimate the mean bone density at the buccal bone.

RESULTS: By the end of the follow- up period, all cases showed normal lower lip sensation, the decrease in level of pain intensity score based on the Visual Analogue Scale (VAS) and an uneventful wound healing with no records of developed infection. Mean bone density after six months showed a statistically significant change in buccal bone density $(\mathrm{p}<0.005)$ and statically non-significant difference in crestal bone density ( $>0.005)$.

CONCLUSION: This study deduced that the use of buccal lid technique in extraction of mandibular bony impacted wisdom results in a predictable and satisfactory outcome, to achieve inferior alveolar nerve preservation and reduce bone defect.

KEY WORDS: Buccal lid, piezosurgery, impacted third molar, surgical extraction.

RUNNING TITLE: Buccal lid piezosurgery in extraction of impactions.
\end{abstract}

1Resident at the Oral and Maxillofacial Surgery Department, Faculty of Dentistry, Alexandria University, Alexandria Egypt.

2Professor of Oral and Maxillofacial Surgery Department, Faculty of Dentistry, Alexandria University, Alexandria Egypt

3Lecturer of Oral and Maxillofacial Surgery Department, Faculty of Dentistry, Alexandria University, Alexandria Egypt

* Corresponding Author:

Email: yassmin.abdelmohsen@gmail.com

\section{INTRODUCTION}

Surgical removal of impacted mandibular third molars is among the most common procedures carried out by oral and maxillofacial surgeons. Impacted mandibular third molars are commonly diagnosed with a reported frequency of $20 \%$ to $30 \%(1)$.

In cases of deeply impacted molars, the removal of the impacted tooth via the conventional approach (i.e. direct osteotomy of the overlying dentoalveolar process) is unpredictable because of limited visibility. Complications such as incomplete extraction, inferior alveolar nerve (IAN) injury, lingual nerve (LN) injury and damage to adjacent teeth may occur (2).

Another technique involves fashioning a bone lid to allow cutting off a window and removing a portion of bone, which is subsequently returned to its original position at the end of the surgical procedure. This technique avoids the formation of large bone defects secondary to access osteotomies $(3,4)$. Thus, it is better to be used in deep impactions than the conventional technique $(5,6)$.
Lately, piezoelectric device was introduced with multiple applications, including bone lid creation. Piezoelectric surgery is an effective technique to perform safe and bone surgeries using piezoelectric ultrasonic vibrations that only cut bone and cause no soft tissue damage by ceasing the surgical action when the scalpel contacts non-mineralized tissues (7-9).

The null hypothesis of this study was that the bone lid technique does not add any additive value or protective benefits over the commonly utilized techniques for the extraction of deeply impacted lower third molars.

Aim of this study is to Evaluate the buccal lid technique using piezotome surgery for removal of deeply impacted third molar, and radiographic evaluation to the site of surgery $6^{\text {th }}$ months later.

\section{MATERIALS AND METHODS}

This was a prospective clinical and radiographic study, that was conducted in the Faculty of Dentistry, Alexandria University. 
The clinical part of the study was performed after gaining the ethical clearance from the Research Ethics Committee, Faculty of Dentistry, Alexandria University.

All patients signed an Informed Consent Form before undergoing the operation to ensure and confirm their understanding of the outcome of the operation and the risks they might be subjected to during the intervention.

\section{Patients}

Ten patients diagnosed with a bony impacted lower third molar have been selected from the outpatient clinic of the Oral and Maxillofacial Surgery department, Faculty of Dentistry, Alexandria University, in the period from June 2018 to April 2019. Inclusion criteria for selection was adults with an age range 25-40 years suffering from class II position C impacted mandibular third molar. The exclusion criteria was any patient with systemic diseases that could interfere with healing or those that had buccal located inferior alveolar nerve in relation to the impacted third molar.

\section{Materials}

Piezotome 2 (Acteon Co., UK) was used for bone cutting, with a recent technology that triples the ultrasonic power in bone surgery, giving rapidity, but keeping cutting selectivity. The bone saw slim tip was used (BS1S).

\section{Methods}

\section{I) Pre-operative assessment and examinations}

A detailed history taking was performed to collect the preoperative and demographic data of the patients, including name, age, gender, occupation, address and past medical history. Followed by a thorough clinical, intraoral and extra-oral examination was performed to record swelling, buccal bone deformity and any tenderness related to the impacted third molar. Panoramic x-ray was done as primary radiographic examination. To evaluate third molar depth, And its relation to the surrounding anatomical structures. Also, a cone beam CT scan was done for each patient before the surgery to evaluate the relation of the impacted tooth to the crest of the alveolar ridge, the neighboring second molar and the inferior alveolar (IA) canal (Fig. 1).

\section{II) Surgical procedure}

Preoperative oral hygiene measures to the patients included prophylactic antibiotic therapy(10) in the form of amoxicillin/clavulanic acid (Augmentin, GSK, UK), 1gram, 2 tablets orally, 1 hour before the operation. The procedure was done under local anesthesia using $2 \%$ mepivacaine $\mathrm{HCl}$ with 1:20,000 levonordefrin (Mepacaine-L, Alexandria Pharmaceutical Co., Egypt) for inferior alveolar nerve block technique.

A full-thickness mucoperiosteal flap was used, starting from the anterior border of the ramus along the second and first molars, followed by a vertical incision mesial to the first molar, extending down to the mucobuccal fold. The flap was reflected to gain access to the underlying bone. (Fig. 2.A).

The buccal bone window was formed as a rectangular shape, using the piezotome tip (BS1S) in a beveled direction through the external buccal cortical plate of bone (Fig. 2.B). The buccal bony lid was freed from its original site, to expose the deeply impacted lower third molar (Fig. 3.A), and preserved in a sterile saline solution till the end of the operation.

The crown of the impacted third molar was then sectioned to facilitate the elevation of the tooth (Fig. 3.B). Then debridement of the surgical site was done before repositioning the buccal lid in its original site and ensuring its stability (Fig.
4.A). The mucoperiosteal flap was repositioned and sutured with 3/0 black silk sutures (Fig. 4.B).

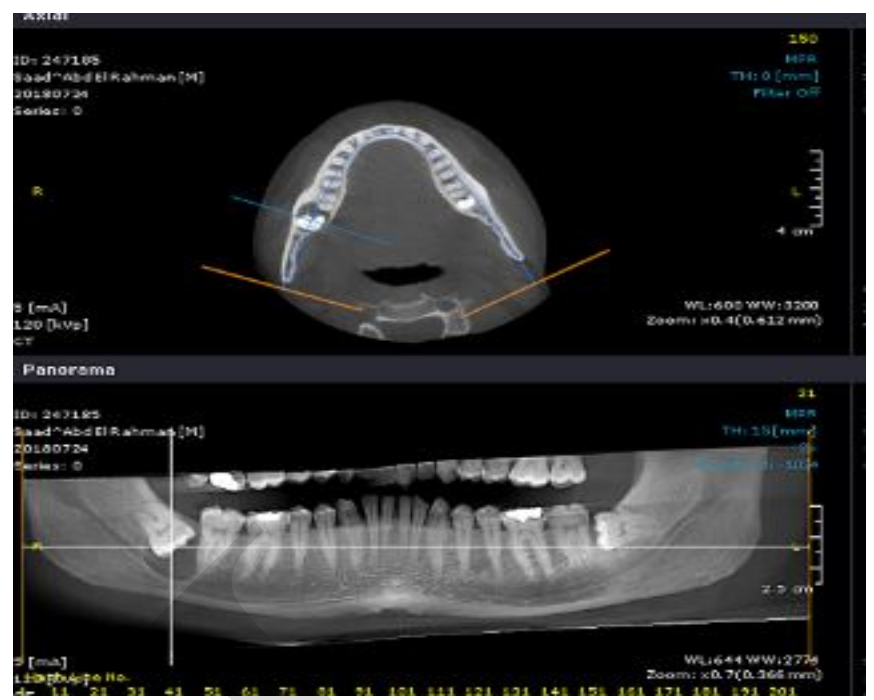

Figure (1): pre-operative CBCT.

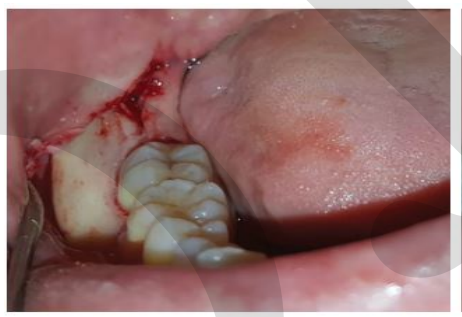

A

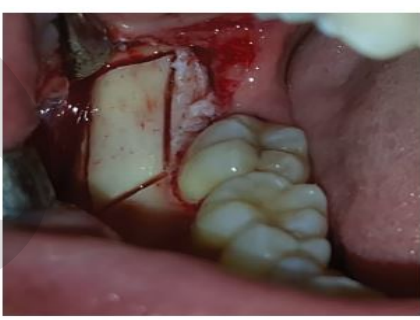

B
Figure (2): (A) Full thikness mucoperisteal flap reflection. (B) Bone lid was prepared using the piezoelectric device.

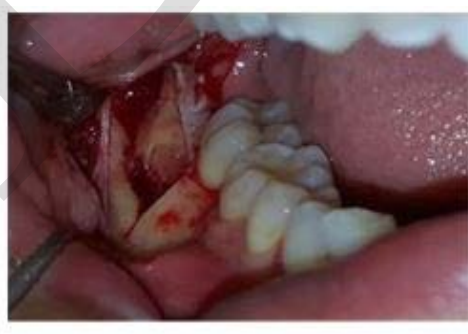

$\Lambda$

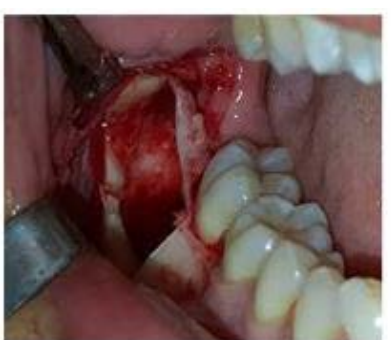

B
Figure (3): (A) Exposure of the impacted tooth. (B) After tooth extraction.

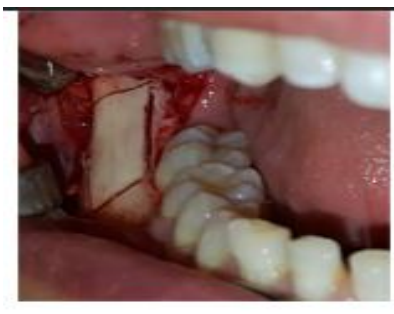

A

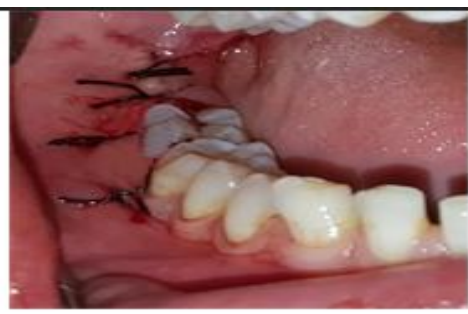

B
Figure (4): (A) Reposition of the buccal bone window. (B) Suturing the flap.

\section{III) Postoperative phase}

All patients were instructed to apply an ice pack extra-orally starting immediately postoperatively for the first 24 hours 
replaced by hot fomentation from second day till the end of the week. Warm saline mouth wash was started the next day till the end of the week with oral hygiene instructions. All patients received oral antibiotics in the form of Amoxicillin $875 \mathrm{mg}+$ Clavulanic acid 125 mg (Augmentin 1gm; GlaxoSmithKline, UK) daily every 12 hours for 5 days after surgery. Analgesic and anti-inflammatory medication in the form Brufen $600 \mathrm{mg}$ was given daily every 8 hours for 5 days.

\section{Follow-up phase}

\section{A-Clinical evaluation}

A postoperative clinical assessment was executed after a 24hours, 48-hours, 72-hours, one week, one month and six months. A postoperative clinical evaluation for pain (assessed by visual analogue scale) (11), post-operative edema (assessed by three lines method) (12) The sum of the three measurements between 5 reference points: tragus, soft tissue pogonion, lateral corner of the eye, angle of the mandible and outer corner of the mouth. Preoperative and postoperative, the difference between them indicated the facial swelling for that day, mouth opening (assessed by measuring inter-incisal distance in $\mathrm{mm}$ ), sensory nerve function(nociceptive method) a dental probe pressure to the mental area to determine any sensory changes in comparison to the contralateral side (13), wound healing and presence of bleeding was performed.

\section{B- Radiographic evaluation}

Six months postoperatively, CBCT was taken and bone density was measured and compared with the preoperative one using Hounsfield units (HU) (Fig. 5).

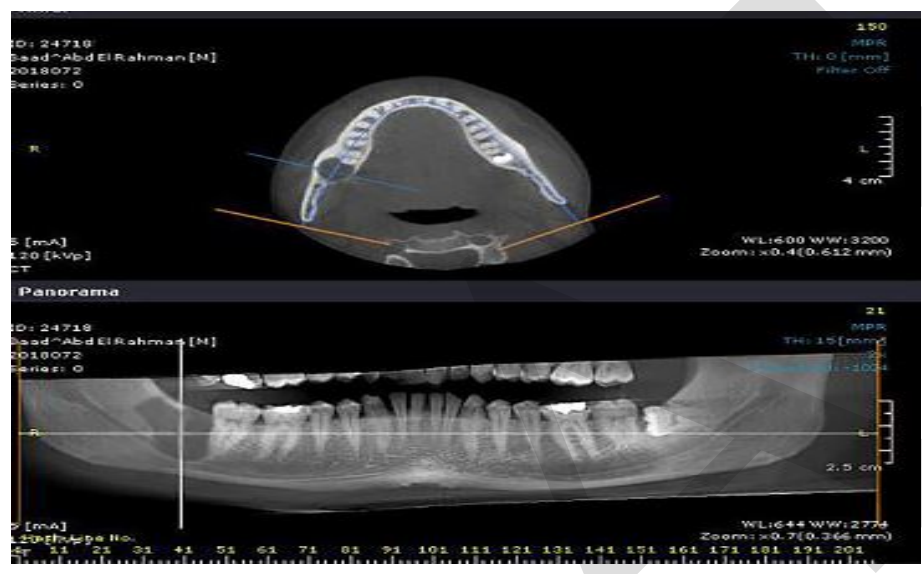

Figure (5): six months post-operative CBCT

\section{Statistical analysis}

All the recorded data were documented, tabulated and statistically analysed using the IBM SPSS software package version 20.0. (Armonk, NY: IBM Corp). Qualitative data were presented by number and percent, while quantitative data were described using range (minimum and maximum), mean, standard deviation and median. The Kolmogorov-Smirnov test was used to verify the normality of data distribution, where the ANOVA with repeated measures test was used for normally distributed quantitative variables, to compare between over two periods or stages, and the Friedman test for the abnormally distributed quantitative variables. The significance of the got results was judged at the $5 \%$ level $(\mathrm{P}<0.05)$.

\section{RESULTS}

\section{Demographic data}

The patients that were selected according to inclusion criteria included 5 males (50\%) and 5 females (50\%) and age ranged from 23 to 40 years with mean (30.70 years \pm 6.06 ).

\section{Clinical data}

Post-operative pain was evaluated using the Visual Analog Scale. The pain was averaged 6.5 after 24 hours postoperatively then declined to 5.1 after 72 hours and reached 0.8 at the end of the first postoperative week. Then the pain disappeared completely afterward (Table 1).

Table (1): Comparison between the three studied periods according

to

VAS $(n=10)$

\begin{tabular}{|c|c|c|c|c|c||}
\hline & \multicolumn{3}{|c||}{ VAS } & \multirow{2}{*}{ Fr } & p \\
\cline { 2 - 4 } & $\begin{array}{c}\text { After } \\
\mathbf{2 4} \\
\text { hours }\end{array}$ & $\begin{array}{c}\text { After } \\
\mathbf{7 2} \\
\text { hours }\end{array}$ & $\begin{array}{c}\text { After 7 } \\
\text { days }\end{array}$ & & \\
\hline $\begin{array}{c}\text { Min. - } \\
\text { Max. }\end{array}$ & $\begin{array}{c}5.0- \\
9.0\end{array}$ & $\begin{array}{c}4.0- \\
7.0\end{array}$ & $\begin{array}{c}0-0- \\
2.0\end{array}$ & & \\
$\begin{array}{l}\text { Mean } \\
\pm \text { SD. }\end{array}$ & $\begin{array}{c}6.50 \pm \\
1.27\end{array}$ & $\begin{array}{c}5.10 \pm \\
1.20\end{array}$ & $\begin{array}{c}0.80 \pm \\
0.79\end{array}$ & $20.0^{*}$ & $<0.001^{*}$ \\
Median & 6.0 & 5.0 & 1.0 & & \\
\hline $\begin{array}{l}\text { Sig. bet. } \\
\text { periods }\end{array}$ & $\mathrm{p}_{1}=0.025^{*}, \mathrm{p}_{2}<0.001^{*}, \mathrm{p}_{3}=0.025^{*}$ & & \\
\hline \hline
\end{tabular}

Fr: Friedman test, Sig. bet. periods was done using Post Hoc Test (Dunn's)

$\mathrm{p}$ : $\mathrm{p}$ value for comparing between the three studied periods $\mathrm{p}_{1}$ : $\mathrm{p}$ value for comparing between after 24 hours and after 72 hours $\mathrm{p}_{2}$ : $\mathrm{p}$ value for comparing between after 24 hours and after 7 days $\mathrm{p}_{3}$ : $\mathrm{p}$ value for comparing between after 72 hours and after 7 days *: Statistically significant at $\mathrm{p} \leq 0.05$

Post-operative edema developed in all patients with variable degrees. It was evaluated by the three lines method. All patients showed slight swelling that was maximum the second postoperative day by (mean $5.42 \mathrm{~mm}$ ) then gradual reduction to 4.8 after third day until it completely disappeared at the end of the first post-operative week (mean $1.9 \mathrm{~mm}$ ), except two patients where edema extended to the end of a second week after surgery (Table 2).

There was no wound dehiscence or signs of infection in the ten patients throughout the follow-up period. Evaluation of presence of numbness at the end of the study period was done, and there was a $100 \%$ response rate to IAN nerve testing. Two patients out of ten had monocortical plate for buccal lid fixation which represented $20 \%$ of cases.

\section{Radiographic data}

Comparison between preoperative and postoperative CBCT for each patient regarding the bone density revealed that on the 6th post-operative month there was a statistically significant change in buccal bone density that ranged from 1234.0 HU to 1694.0 HU with a mean of $(1508.4 \pm 166.2)$ $(\mathrm{p}<0.005)$ showing $11.1 \%$ change in bone density. (Table 3$)$ (fig.6)

Crestal bone density after 6 months ranged from $630.0 \mathrm{HU}$ to $1493.0 \mathrm{HU}$ by mean $(1008.1 \pm 356.0)$ as $7.03 \%$ changing in bone density. This presents a statically non-significant difference in crestal bone density (Table 3) (fig.6). 
Table (2): Comparison between the three studied periods according to post-operative odema $(n=10)$

\begin{tabular}{|c|c|c|c|c|c|}
\hline & \multicolumn{3}{|c|}{ Post-operative odema } & \multirow[b]{2}{*}{$\mathbf{F}$} & \multirow[b]{2}{*}{$\mathbf{p}$} \\
\hline & $\begin{array}{c}\text { After } \\
24 \\
\text { hours }\end{array}$ & $\begin{array}{c}\text { After } \\
72 \\
\text { hours }\end{array}$ & $\begin{array}{c}\text { After } 7 \\
\text { days }\end{array}$ & & \\
\hline \multirow{3}{*}{$\begin{array}{l}\text { Min. - Max. } \\
\text { Mean } \pm \text { SD. } \\
\text { Median }\end{array}$} & $4.70-6.40$ & $3.80-6.20$ & $0.20-4.50$ & \multirow{3}{*}{$115.730^{*}$} & \multirow{3}{*}{$<0.001$} \\
\hline & $5.42 \pm 0.68$ & $4.81 \pm 0.82$ & $1.97 \pm 1.32$ & & \\
\hline & 5.20 & 4.55 & 1.65 & & \\
\hline \begin{tabular}{|l} 
Sig. bet. \\
periods
\end{tabular} & \multicolumn{3}{|c|}{$\mathrm{p}_{1}<0.001^{*}, \mathrm{p}_{2}<0.001^{*}, \mathrm{p}_{3}<0.001^{*}$} & & \\
\hline
\end{tabular}

F: F test (ANOVA) with repeated measures, Sig. bet. periods was done using Post Hoc Test (Bonferroni)

$\mathrm{p}$ : $\mathrm{p}$ value for comparing between the three studied periods $\mathrm{p}_{1}$ : $\mathrm{p}$ value for comparing between after 24 hours and after 72 hours $\mathrm{p}_{2}$ : $\mathrm{p}$ value for comparing between after 24 hours and after 7 days $\mathrm{p}_{3}$ : $\mathrm{p}$ value for comparing between after 72 hours and after 7 days

*: Statistically significant at $\mathrm{p} \leq 0.05$

Table (3): Comparison between before and after according to bone density.

\begin{tabular}{|c|c|c|c|c|}
\hline Bone density & $\begin{array}{c}\text { Before } \\
(\mathrm{n}=10)\end{array}$ & $\begin{array}{c}\text { After } \\
(n=8)\end{array}$ & $\begin{array}{l}\text { Test of } \\
\text { sig. }\end{array}$ & $\mathbf{p}$ \\
\hline $\begin{array}{l}\text { Crest } \\
\text { Min. - Max. } \\
\text { Mean } \pm \text { SD. } \\
\text { Median }\end{array}$ & $\begin{array}{c}755.0-1630.0 \\
1084.3 \pm 360.7 \\
960.5 \\
\end{array}$ & $\begin{array}{c}630.0-1493.0 \\
1008.1 \pm 356.0 \\
1004.0 \\
\end{array}$ & $\begin{array}{c}Z= \\
1.400\end{array}$ & 0.161 \\
\hline$\Delta$ Change & \multicolumn{2}{|c|}{$\downarrow 76.2$} & & \\
\hline \% Change & \multicolumn{2}{|c|}{$\downarrow 7.03 \%$} & & \\
\hline \begin{tabular}{l}
\multicolumn{1}{c}{ Buccel } \\
Min. - Max. \\
Mean \pm SD. \\
Median \\
\end{tabular} & $\begin{array}{c}1424.0- \\
1946.0 \\
1696.7 \pm 155.1 \\
1728.5 \\
\end{array}$ & $\begin{array}{c}1234.0- \\
1694.0 \\
1508.4 \pm 166.2 \\
1565.0 \\
\end{array}$ & $\begin{array}{c}t= \\
2.968^{*}\end{array}$ & $0.021^{*}$ \\
\hline$\Delta$ Change & \multicolumn{2}{|c|}{$\downarrow 188.3$} & & \\
\hline \% Change & \multicolumn{2}{|c|}{$\downarrow 11.1 \%$} & & \\
\hline
\end{tabular}

Z: Wilcoxon signed ranks test t: Paired t-test

$\mathrm{p}$ : $\mathrm{p}$ value for comparing between before and after

*: Statistically significant at $\mathrm{p} \leq 0.05$

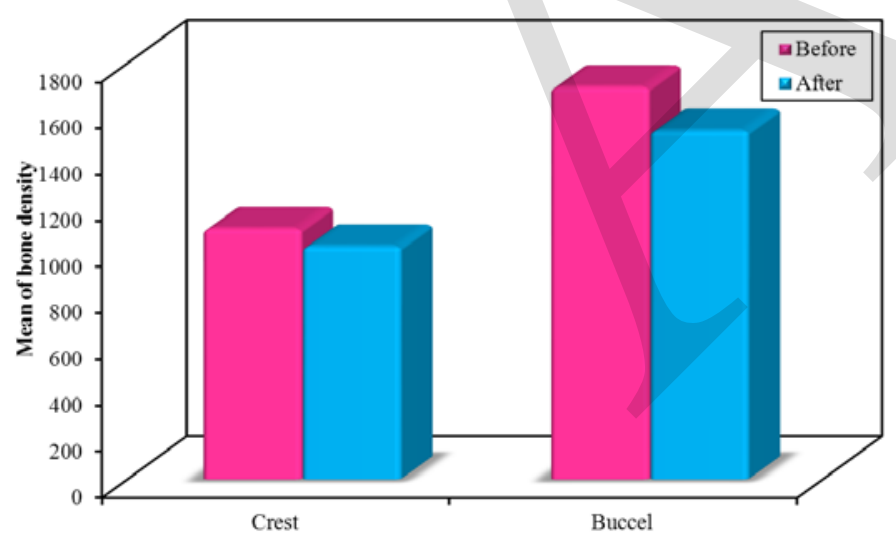

Figure (6): Comparison between before and after according to bone density.

\section{DISCUSSION}

This study was planned as a prospective clinical and radiographic evaluation of the piezosurgery-performed buccal bone lid technique for the extraction of deeply impacted mandibular third molar using an intra-oral approach.
As mentioned, IAN injuries are a major concern while performing extractions of impacted mandibular teeth, with its following morbidities (14). This increase while dealing with unusual and deep impactions of mandibular molars for great proximity between the tooth and the IAN. The locations of the impactions were not accessible with the conventional approach. The removal of buccal bone window provided superb access to the impacted tooth with excellent visibility of the entire surgical site, safe separation and removal of the teeth without nerve injury and without applying excessive forces over the bone. These judgments were made clear in this study by the non-existence of subjectively reported or objectively noted nerve injury or paraesthesia.

The selective cutting properties of the peizosurgery had a major role in the avoidance of an iatrogenic traumatization to the IAN as once again reported in all the study cases.

The mean preoperative buccal bone estimated density was $1696.7 \pm 155.1$ HU. This value showed a statistically significant change in the 6-month postoperative scan $(\mathrm{p}<0.021)$, where the mean calculated bone density was $1508.4 \pm 166.2 \mathrm{HU}$.

The estimated crestal bone density values, the preoperative scans reported a mean of $1084.3 \pm 360.7 \mathrm{HU}$, while the postoperative ones disclosed a mean value of 1008.1 \pm 356.0 . The difference in the estimated crestal bone density values was statistically insignificant.

Despite the decrease in the recorded buccal bone density in the postoperative scan, the recorded values fall in the normal physiological values reported at this area with D1 bone quality. This may show a normal bone healing with preservation of the buccal contour of the alveolar bone. Similar values were reported in the crestal bone values, indicating once again a satisfactory bone healing outcome.

To our knowledge, this study differed from the pioneer study done by Alling and Alling (15) in the manner and the bone cutting device utilized during the bone-window creation. Alling and Alling (15) used a surgical bur mounted on an airdriven motor, this create bone osteotomy with none controlled width, depth or margins along with apparent bone loss. This study utilized a piezotome with bone cutting tips to create the osteotomy. The bone osteotomy tips of piezotome facilitate the production of sharp and thin osteotomy lines with a predictable and controllable depth. The working piezotome tips is of a cutting width of only $0.1-0.2 \mathrm{~mm}$. This results in an osteotomy with a miniature width and maximum bone preservation with less heat generation (4).

The favorable outcome related to the preservation of the IAN may be contributed to the selective cutting nature of the piezotome tip, which is an inherited proprietary feature in the pizosurgery that is not found in the conventional bone cutting method (4). The piezotome cuts only within bony structures and it won't cut in soft tissue. This safety feature may be culpable for the favorable outcomes by this study regarding the IAN preservation.

The use of buccal bone lid technique in removal of deeply impacted lower third molar allow excellent accessibility with no need for a significant amount of bone to be sacrificed and turned into dead space. In contrast to Wagner et al. who described the drawbacks of traditional buccal approach as a lack of accessibility, bone loss and nerve injury(16).

Guttering in this technique is not indicated because preservation of bone is preferred in this case, that allow the 
buccal window replaced in its position at the end of the surgery by friction and supported on the remaining bone so we need to extend the window in the surgery to facilitate its reposition without using plates. The bur in this study was only used for tooth sectioning and not for bone guttering.

In this study there was no need for intermaxillary fixation (IMF) after surgery and only two cases need mono cortical plates postoperatively. This outcome is in contrast with that encountered by Sencimen et al; who reported the use of IMF for 4 weeks postoperative and plate in all cases while utilizing the sagittal split osteotomy (SSO) technique in the extraction of deeply impacted lower third molar (17).

In 2001, Renton and McGurk discussed the lingual split technique in extraction of lower third molar with high risk of lingual nerve damage and lingual plate of bone fracture. In buccal lid technique there is no risk of injury to the lingual nerve as it is away from the field and no indications for the lingual plate of bone fracture (18).

Dysphagia develops following surgical removal of mandibular molars because of the need for soft tissue flap elevation and bone reduction at the lingual side of the tooth. This in turn results in a postoperative swelling of the lingual tissues (19). We reckon that the overall incidence and severity of dysphagia is associated directly with the depth of impaction. With, the buccal lid approach the lingual tissues remain intact. Sequentially, this eliminates the postoperative dysphagia, and the associated discomfort.

The excessive lingual surgical exposure during the conventional surgery also increases the possibility of lingual nerve injury. Every surgical incision located too far lingually or penetrating the lingual cortex with a surgical bur may injure the LN (20). Once lingual nerve is damaged, amongst other complaints, the patient will report of drooling and changes while swallowing (16). Thus, another important advantage of the buccal window approach derives from the noninvolvement of the lingual tissues.

\section{CONCLUSION}

It was concluded from this study that the utilization of buccal lid technique for the extraction of bony impacted mandibular third molars is an effective method with better bone healing outcomes and provides a safer alternative for the extraction of deeply impacted wisdom while minimizing the risk of iatrogenic IAN or LN injury.

\section{Conflict of Interest}

The authors declare that they have no conflict of interest.

\section{REFERENCES}

1. Abu-El Naaj I, Braun R, Leiser Y, Peled M. Surgical approach to impacted mandibular third molars--operative classification. J Oral Maxillofac Surg. 2010;68:628-33.

2. Kan KW, Liu JK, Lo EC, Corbet EF, Leung WK. Residual periodontal defects distal to the mandibular second molar 6-36 months after impacted third molar extraction. J Clin Periodontol. 2002;29:1004-11.

3. Kontaxis KL, Steinbacher DM, Access to the mandibular angle using a sagittal split to address pathologic displacement of a mandibular third molar, J Oral Maxillofac Surg. 2015;73:2285.e1-5.
4. Khoury F. The bony lid approach in pre-implant and implant surgery: A prospective study. Eur J Oral Implantol. 2013;6:375.

5. Degerliyurt K, Akar V, Denizci S, Yucel E. Bone lid technique with piezosurgery to preserve inferior alveolar nerve. Oral Surg Oral Med Oral Pathol Oral Radiol Endod. 2009;108:e1.

6. Sivolella S, Brunello G, Berengo M, De Biagi M, Bacci C. Rehabilitation with implants after bone lid surgery in the posterior mandible. J Oral Maxillofac Surg. 2015;73:1485-92.

7. Esposito M, Grusovin MG, Felice P, Karatzopoulos $\mathrm{G}$, Worthington $\mathrm{HV}$, Coulthard P. Interventions for replacing missing teeth: Horizontal and vertical bone augmentation techniques for dental implant treatment. Cochrane Database Syst Rev. 2009;:CD003607.

8. Pappalardo S, Guarnieri R. Randomized clinical study comparing piezosurgery and conventional rotatory surgery in mandibular cyst enucleation. $\mathrm{J}$ Craniomaxillofac Surg. 2014;42:e80-5.

9. Younes R, Nasseh I, Lahoud P, Wassef E, Dagher M. Bone Lid Technique Using a Piezoelectric Device for the Treatment of a Mandibular Bony Lesion. Case Rep Dent. 2017;2017:9315070.

10. ADA. Antibiotic prophylaxis prior to dental procedures. Oral Health Topics 2017 [cited 31st March 2017]; Available from: http://www.ada.org/en/member-center/ oral-health-topics/antibiotic-prophylaxis

11. Johnson C. Measuring Pain. Visual Analog Scale Versus Numeric Pain Scale: What is the Difference? J Chiropr Med 2005;4:43-4.

12. Bello, S. A., Adeyemo, W. L., Bamgbose, B. O., Obi, E. V., \& Adeyinka, A. A. (2011). Effect of age, impaction types and operative time on inflammatory tissue reactions following lower third molar surgery. Head \& Face Medicine, 7(1), 8.

13. Kotrashetti, S. M., \& Singh, A. G. (2017). Prospective study of treatment outcomes with lag screw versus Herbert screw fixation in mandibular fractures. International Journal of Oral and Maxillofacial Surgery, 46(1), 54-58.

14. Cheung LK, Leung YY, Chow LK, Wong MC, Chan EK, Fok YH. Incidence of Neurosensory Deficits and Recovery after Lower Third Molar Surgery: A Prospective Clinical Study of 4338 Cases. Int J Oral Maxillofac Surg. 2010;39:320-6.

15. Alling R, Alling CC. Removal of Impacted Teeth and Lesions from Unusual Locations. J Oral Maxillofac Surg. 1993; 5:111- 9 .

16. Wagner $\mathrm{K}$, et al. "Pathological mandibular fractures following third molar removal. International journal of oral and maxillofacial surgery 34.7 (2005): 722-726.

17. Sencimen M, Varol A, Gülses A, Altug HA. Extraction of a deeply impacted lower third molar by sagittal split osteotomy. Oral Surg Oral Med Oral Pathol Oral Radiol Endod. 2009;108: e36-8.

18. Renton T, and M. McGurk. Evaluation of factors predictive of lingual nerve injury in third molar surgery. British Journal of Oral and Maxillofacial Surgery 39.6 (2001): 423-428.

19. Ness GM. Impacted Teeth. In: Miloro M, Peterson LJ. Peterson's Principles of oral and Maxillofacial Surgery. $3^{\text {rd }}$ ed. Shelton, CT: People's Medical Pub. House-USA; 2011. 
20. Ziccardi VB1, Zuniga JR. Nerve Injuries after Third Molar Removal. Oral Maxillofac Surg Clin North Am. 2007;19:105-15, vii. 